Artigo / Article

\title{
Deformabilidade eritrocitária na anemia ferropriva
}

\section{Erythrocyte deformability in iron deficiency}

\author{
Giuseppina M. Patavino ${ }^{1}$ \\ Paulo A. Silveira ${ }^{2}$ \\ Sandra F. M. Gualandro ${ }^{3}$ \\ Iara K. Yokomizo ${ }^{3}$ \\ Deise M. T. Moromizato ${ }^{2}$
}

\begin{abstract}
A deformabilidade é a característica que permite ao eritrócito normal de 7 a 8 micrômetros $(\mu \mathrm{m})$ circular por capilares de até $3 \mu \mathrm{m}$ de diâmetro. Esse fenômeno depende da geometria celular, da viscosidade interna e de propriedades visco-elásticas da membrana eritrocitária. Dentre as técnicas de estudo da deformabilidade eritrocitária (DE), como aspiração por micropipeta, filtração e reoscopia, destaca-se a ectacitometria. Esta técnica utiliza um viscosímetro de fluxo laminar no qual as modificações de forma dos eritrócitos são monitoradas continuamente por um feixe de raio laser, processadas por microcomputador, gerando o "Índice de Deformabilidade" (ID), que mede a eliptocitogênese dos eritrócitos quando submetidos a uma força denominada "shear stress". Alterações de DE foram descritas em diversas situações, como em anemias hemolíticas hereditárias ou auto-imunes. Na anemia ferropriva, os trabalhos são controversos. O presente estudo avalia a DE em 21 pacientes portadores de anemia ferropriva, utilizando a ectacitometria. Os resultados obtidos a partir do ID demonstram DE diminuída nesses doentes, quando comparada ao grupo controle $(p<0,0007)$. O presente estudo sugere que o fator responsável pela diminuição da DE na anemia ferropriva é a microcitose. Recentemente, relatos desta anemia associada a fenômenos trombóticos aumentaram o interesse no estudo da DE para melhor entendimento desses casos. Rev. bras. hematol. hemoter. 2006;28(4):253-257.
\end{abstract}

Palavras-chave: Deformabilidade eritrocitária; ectacitometria; índice de deformabilidade; anemia ferropriva.

\section{Introdução}

O termo deformabilidade eritrocitária é utilizado para caracterizar a propriedade de adaptação dos glóbulos vermelhos ao fluxo durante os 120 dias (em média) que permanece na circulação. Esse fenômeno complexo depende de três fatores: geometria celular, viscosidade intracitoplasmática e propriedades mecânicas da membrana. ${ }^{1}$

Na última década foram observados alguns casos graves de tromboses cerebrais associados à anemia ferropriva, em especial nas crianças. Esta tem sido apontada como causa provável da diminuição da deformabilidade eritrocitária, com conseqüente alteração reológica do sangue na microcirculação. Alguns autores sugerem que na anemia ferropriva ocorra uma redução na sobrevida da hemácia microcítica e hipocrômica e que um dos principais fatores seria a sua menor flexibilidade. Este fato estaria relacionado com o menor conteúdo interno de hemoglobina e uma relação desfavorável superfície/volume da célula, com conseqüente seqüestro precoce pelo sistema retículo-endotelial. .,3,4,5 $^{2,4}$

A ectacitometria é uma técnica viscosimétrica que permite o estudo dos diversos determinantes da deformabilidade eritrocitária, sendo possível avaliar a relação área de superfície/volume e a geometria celular. Foi inicialmente descrita por Bessis e Mohandas, em 1974, e posteriormente utilizada por diversos autores tanto em animais como em seres humanos com diferentes patologias. . $^{6-11}$

O objetivo desse estudo é avaliar a deformabilidade

${ }^{1}$ Disciplina de Hematologia do Centro Universitário Lusíada / Hemonúcleo de Santos. ${ }^{2}$ Serviço de Hematologia do Hospital das Clínicas da Faculdade de Medicina da USP.

${ }^{3}$ Disciplina de Hematologia da Faculdade de Medicina da USP.

Correspondência: Giuseppina Maria Patavino

Av. Ana Costa 464 conj 35 - Gonzaga

11060-002 - Santos-SP - Brasil

Tel/Fax: (13) 3284-8246

E-mail: pinap@vipway.com.br 
eritrocitária em portadores de anemia ferropriva com a técnica da ectacitometria.

\section{Material e Métodos}

Foram avaliados 21 pacientes com anemia ferropriva acompanhados no Ambulatório de Hematologia do Hemonúcleo de Santos-SP, no período de 01 de outubro de 2000 a 20 de novembro de 2001.

Os critérios de inclusão foram: a presença de anemia ( $\mathrm{Hb}<12,0 \mathrm{~g} / \mathrm{dl}$ ) e ferropenia (ferro sérico $<75 \mu \mathrm{g} / \mathrm{dl}$ ); capacidade total de ligação de ferro no plasma (> $250 \mu \mathrm{g} / \mathrm{dl}$ ); saturação de ferro $(<20 \%)$ e ferritina $(<24 \mathrm{ng} /$ dl para homens e $<11 \mathrm{ng} / \mathrm{dl}$ para mulheres). Os pacientes com hemoglobinopatia associada foram previamente excluídos.

A hemoglobina inicial variou de 5,8 a 11,0 g/dl (média de $8,52 \mathrm{~g} / \mathrm{dl}$ ), e o hematócrito oscilou entre $22,1 \%$ a $37,0 \%$ (média de 30,91\%). Após o tratamento com sais de ferro, houve melhora dos níveis de hemoglobina e hematócrito em todos os pacientes, que apresentaram valores de hemoglobina de 11,0 a 13,9 g/dl (média de 12,74 g/dl) e hematócrito de 37,8 a 53,2\% (média de 42,29\%).

A carência de ferro dos pacientes foi documentada pelos seguintes resultados antes do tratamento: dosagem de ferro de 8 a $42 \mu \mathrm{g} / \mathrm{dl}$ (média de 17,85 $\mu \mathrm{g} / \mathrm{dl}$ ); CTLF de 283 a $449 \mu \mathrm{g} / \mathrm{dl}$ (média de 388,66 $\mu \mathrm{g} / \mathrm{dl}$ ); saturação de ferro de 1,0 a 9,0\% (média de 4,19\%) e dosagem de ferritina de 1,0 a $30,0 \mathrm{ng} / \mathrm{ml}$ (média de 5,8 ng/ml). Os valores encontrados após o tratamento foram: dosagem de ferro de 17,0 a 198,0 $\mu \mathrm{g} / \mathrm{dl}$ (média de

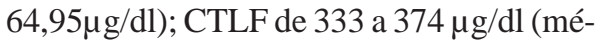
dia de $312,76 \mu \mathrm{g} / \mathrm{dl}$ ); saturação de ferro de 5,0 a $82,0 \%$ (média de $21,61 \%$ ) e dosagem de ferritina de 5,0 a 412,0 ng/ml (média de $45,0 \mathrm{ng} / \mathrm{ml})$.

Os exames antes e depois do tratamento foram realizados no Laboratório de Hematologia da Disciplina de Hematologia e Hemoterapia da Faculdade de Medicina da Universidade de São Paulo-USP/ Fundação Pró-Sangue/ Hemocentro de São Paulo. Um grupo de 21 doadores de sangue por aférese foi escolhido aleatoriamente para ser o controle.

A deformabilidade dos glóbulos vermelhos foi determinada em vários shear stress por um ectacitômetro LORCA ${ }^{\circledR}$ (LaserAssisted Optical Rotational Cell Analyser) versão 1.0, da RR Mechatronics, Amsterdan. O instrumento consiste em um diodo a laser, um sistema de recipientes de vidro com termostato, um motor e uma câmara de vídeo acoplada a um microcomputador. A amostra é depositada no espaço de $3 \mathrm{~mm}^{3}$ compreendido entre os dois cilindros de vidro. O microcomputador é programado para controlar a velocidade do cilindro interno, assim como a temperatura ideal. O laser é projetado perpendicularmente à amostra e o padrão de difração produzido pelos glóbulos vermelhos é analisado pelo computador.

As alterações de ID refletem mudanças da deformabilidade de células individuais. Quanto maior o ID, mais deformável é o eritrócito. O ID é calculado para cada shear stress em unidade de tensão Pascal: 0,3- 0,53- 0,95-1,69- 3,05,34- 9,48-16,86 e 30,05.

\section{Resultados}

Os resultados deste estudo evidenciaram que a deformabilidade eritrocitária, determinada pelo "Índice de Deformabilidade" pela ectacitometria, mostrou-se diminuída na anemia ferropriva.

A Figura 1 mostra os valores médios do ID na suspensão de 300 mOsm, em shear stress progressivo, dos controles e dos pacientes portadores de anemia ferropriva antes do tratamento. Observa-se uma diferença estatisticamente significante após o shear stress de 0,95 $\mathrm{Pa}(\mathrm{p}<0,0007)$. Os resultados obtidos demonstram diminuição da deformabilidade eritrocitária na anemia por deficiência de ferro.

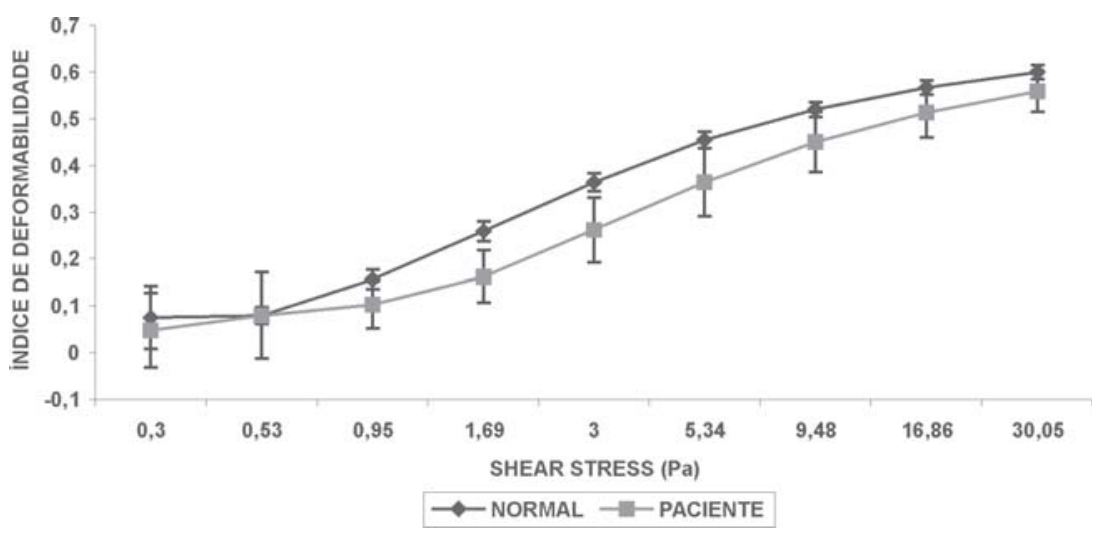

Figura 1. ID no grupo controle e nos pacientes pré-tratamento

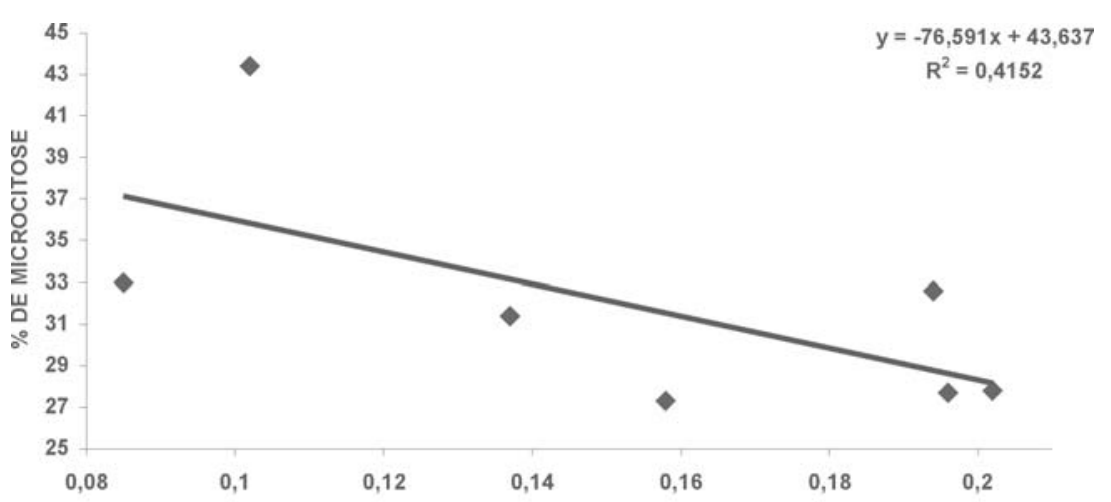

Figura 2. Correlação entre microcitose acima de $20 \%$ e ID 
Observa-se na Figura 2 que nos pacientes com microcitose acima de 20\%, o "Índice de Deformabilidade" tende a ser menor nos diversos shear stress.

\section{Discussão}

A Organização Mundial da Saúde estima que 4 a 5 bilhões de pessoas no mundo apresentem algum grau de deficiência de ferro e conseqüente anemia em cerca de 2 bilhões. ${ }^{12}$

A anemia ferropriva é uma ocorrência bastante comum na prática médica que se caracteriza por alterações morfológicas acentuadas dos glóbulos vermelhos. A anisocitose é o sinal mais precoce seguido do aparecimento de hemácias microcíticas e hipocrômicas, conforme o agravamento do caso. Ocorre ainda a presença de ovalócitos, eliptócitos e, mais raramente, hemácias "em alvo". Todas essas alterações dependem do grau da anemia e do tempo de evolução do quadro. ${ }^{13}$

Os trabalhos relativos à ectacitometria disponíveis na literatura têm sido controversos, pois as diferentes técnicas utilizadas para medir a deformabilidade eritrocitária não podem ser comparadas entre si.

Diversos autores interessados na reologia eritrocitária são unânimes em afirmar que há necessidade de mais estudos dessa propriedade do eritrócito, uma vez que existe uma interação dos fatores responsáveis pela deformabilidade da hemácia. ${ }^{14,15}$

Dessa maneira, a diminuição da deformabilidade eritrocitária na anemia ferropriva estaria relacionada com a maior rigidez da membrana e com a geometria celular alterada do micrócito. A viscosidade intracelular pode, em determinadas condições, compensar esses dois fatores, tornando a célula mais "fluida" e assim aumentar a sua deformabilidade. ${ }^{16-20}$

A "geometria celular" depende da forma, do volume e da relação superfície/volume do eritrócito. A conformação discóide proporciona ao glóbulo vermelho normal um vantajoso excesso de superfície em relação ao volume, o que facilita a sua adaptação quando necessário. A "viscosidade intracitoplasmática" depende da concentração de hemoglobina e de propriedades físico-químicas. ${ }^{21}$

A "membrana citoplasmática" desempenha uma função primordial na habilidade de deformação dos eritrócitos, além de manter sua integridade estrutural. Para que o eritrócito mantenha essa capacidade, é necessário que ela esteja com todos os seus constituintes quantitativa e qualitativamente normais. As anormalidades na fração lipídica, nas proteínas integrais (glicoforina, Banda 3) e principalmente nas proteínas do citoesqueleto (espectrinas, proteína 4.1, anquirina e outras) alteram a deformabilidade do eritrócito. ${ }^{22,23}$

Sabe-se que a deformabilidade está diminuída em eritrócitos senescentes e em anemias hemolíticas como anemia falciforme, hemoglobinopatia $\mathrm{C}$, talassemias, microesferocitose hereditária, eliptocitose hereditária, deficiência de glicose-6-fosfato-desidrogenase e anemias hemolíticas auto-imunes. ${ }^{24,25,26}$
Algumas técnicas permitem avaliar a reologia e a deformabilidade eritrocitária, embora muitas delas permaneçam restritas a poucos centros de pesquisa.

Os principais métodos de estudo da deformabilidade eritrocitária são a aspiração por micropipeta, a filtração e a viscometria. A aspiração com micropipeta é feita por aplicação de pressão negativa sobre a membrana eritrocitária, fazendo com que a célula penetre na luz da mesma. É uma técnica trabalhosa e que permite apenas o estudo de células individualizadas. ${ }^{1}$

A filtração está fundamentada na passagem de uma amostra de sangue em filtros com poros de diversos tamanhos, aplicando-se uma pressão constante. Quando se analisa o sangue total por este método, pode haver influência de outros elementos como proteínas plasmáticas, leucócitos e plaquetas, o que limita o seu uso. ${ }^{14,16}$

Os métodos viscosimétricos utilizam uma suspensão de hemácias sob efeito de uma tensão, num aparelho denominado viscosímetro. Nessas condições, os eritrócitos discóides tornam-se elípticos, com o seu maior eixo paralelo ao sentido do fluxo. Essa técnica permite a observação direta das modificações da célula, denominada reoscopia. Além disso, pode-se medir o grau de deformabilidade em função da tensão aplicada através da técnica da ectacitometria. ${ }^{25}$

O ectacitômetro é um instrumento versátil e sofisticado, com a vantagem de usar uma pequena quantidade de sangue e coeficiente de variação próximo de $1 \%$, o que aumenta a sua sensibilidade. A expressão shear stress tem sido traduzida na literatura nacional como tensão ou força de "cisalhamento" ou "tosquiamento". O shear stress na circulação normal é definido como a força de resistência tangencial produzida pelo movimento do sangue na superfície vascular endotelial. Sua magnitude é diretamente proporcional ao fluxo e à viscosidade do sangue e inversamente proporcional ao cubo do seu raio. ${ }^{6,9}$

No ectacitômetro, o shear stress é fixo e não existe variação do recipiente onde a amostra é analisada. Assim, as alterações observadas dependem das modificações próprias dos glóbulos vermelhos. Estes geram em repouso um padrão de difração circular no ectacitômetro, ocorrendo a transformação elíptica e orientação paralela ao fluxo quando submetidos à tensão. ${ }^{9}$

A avaliação da densidade óptica, entre os pontos de maior e menor difração gerada pelo ectacitômetro-LORCA ${ }^{\circledR}$, determina o "Índice de Deformabilidade" (ID) ou "Índice de Elongação" (IE), o qual proporciona uma medida direta da eliptocitogênese. Um valor numérico de zero significa que não há deformação, enquanto os índices positivos são progressivamente proporcionais à deformabilidade celular. ${ }^{9}$

A ectacitometria permite a análise das células em diferentes condições de tonicidade, quando associada a um gradiente de osmolalidade. É uma técnica que permite o estudo dos diversos determinantes da deformabilidade 
eritrocitária, sendo possível avaliar a relação superfície/ volume, a geometria celular, a densidade celular e a membrana citoplasmática. ${ }^{9}$

A análise da deformabilidade eritrocitária pela ectacitometria tem sido considerada "padrão ouro" dentre as técnicas existentes e representa o passo mais importante para o diagnóstico nas patologias por defeito de membrana. ${ }^{9,10,22,24}$ Entretanto, foram encontrados raros trabalhos publicados a respeito de deformabilidade eritrocitária na anemia ferropriva.

Tillmann ${ }^{17}$ utilizou a filtração e sugeriu que a redução da flexibilidade da hemácia microcítica ocorreria por maior fluidez conseqüente ao menor conteúdo de hemoglobina.

A observação de 21 pacientes com anemia ferropriva quando comparados com controles normais mostrou diminuição da deformabilidade eritrocitária antes do tratamento convencional. Não foi verificada correlação entre o grau da anemia e a redução da DE. ${ }^{27}$

Vaya ${ }^{28}$ verificou uma diminuição no índice de elongação por ectacitometria em anemia ferropriva devido a alterações de superfície/ volume das hemácias. Esta pesquisa relata ainda que essa técnica é bastante útil e sensível.

O presente estudo demonstrou que, na anemia ferropriva a deformabilidade eritrocitária está diminuída quando comparada a um grupo controle de doadores de sangue por aférese. Dos fatores determinantes da deformabilidade eritrocitária, a geometria celular representada pela porcentagem de micrócitos parece ser o componente mais importante na carência de ferro.

Recentemente, algumas publicações relacionaram a deformabilidade eritrocitária a situações clínicas como tromboses, pré-eclâmpsia, nefropatia diabética, erisipela e outras. O método viscosimétrico da ectacitometria foi o mais utilizado, o que sugere a necessidade de novos estudos e uma maior familiaridade com essa técnica. ${ }^{29-33}$

A ectacitometria foi bastante sensível às alterações eritrocitárias e de fácil reprodução. A avaliação da deformabilidade das hemácias pode levar a um melhor entendimento da fisiopatologia de diversas doenças comuns na prática médica.

\section{Abstract}

Deformability allows the 7 to $8 \mu \mathrm{m}$ red cell to cirDeformability allows the 7- to 8- $\mu \mathrm{m}$ red blood cells to circulate through capillaries of $3 \mu \mathrm{m}$. This phenomenon depends on cellular geometry, internal viscosity and viscoelastic properties of the membrane. Among the various techniques of erythrocyte deformability analysis, such as micropipette aspiration, filtration and reoscopy, we chose ektacytometry. This technique uses a laminar flow viscometry, where red blood cell shape changes are continuously monitored by laser, processed by a computer, generating the "Deformability Index", which shows the elliptocytogenesis of the erythrocyte under "shear stress" force. Erythrocyte deformability has been described in a number of situations like hereditary or autoimmune hemolytic anemia. In respect to iron deficiency anemia, conclusions are controversial. The present study evaluates erythrocyte deformability in 21 patients with documented iron deficiency, using ectacytometry. Results obtained from deformability Index demonstrate diminished erythrocyte deformability in individuals with iron deficiency anemia, when compared to a control group ( $p<0.0007)$. The present study suggests that the factor responsible for diminished erythrocyte deformability in iron deficiency is microcytosis. Recently, this anemia has been associated to thrombotic phenomenon, which has raised interest in the study of erythrocyte deformability, in order to understand these cases. Rev. bras. hematol. hemoter. 2006; 28(4): 253-257.

Key words: Erythrocyte deformability; ektacytometry; deformability index; iron deficiency..

\section{Referências Bibliográficas}

1. Mohandas N, Chasis JA. Red blood cell deformability, membrane material properties and shape: regulation by transmembrane, skeletal and cytosolic proteins and lipids. Semin Hematol 1993; 30:171-92.

2. Hartfield DS, Lowry NJ, Keene DL, Yager JY. Iron deficiency: a cause of stroke in infancts and children. Pediatr Neurol 1997; 16:50-3.

3. Meena AK, Naidu KS, Murthy JMK. Cortical sinovenous thrombosis in a child with nephrotic syndrome and iron deficiency anaemia. Neurol India 2000;48:292-94.

4. Chan AKC, Veber G. Prothrombotic disorders and ischemic stroke in children. Semin Pediatr Neurol 2000;7:301-8.

5. Kacer B, Hattenbach LO, Hörle S, Scharrer I, Kroll P, Koch F. Central retinal vein occlusion and nonarteritic ischemic optic neuropathy in 2 patients with mild iron deficiency anemia. Ophthalmologica 2001;215:128-31.

6. Bessis N, Mohandas N. Mesure continue de la déformabilité cellulaire par une méthode diffractométrique. C R Acad Sci Paris 1974; 278: 3.263-65.

7. Mazeron P, Muller S, Azouzi H. Deformation of erythrocytes under shear: a small- angle light scattering study. Biorheology 1997;34:99-110.

8. Streekstra GJ, Hoekstra AG, Nijhof EJ, Heethaar RM. Light scattering by red blood cells in ektacytometry: Fraunhofer versus anomalous diffraction. Applied Optics 1993;2.266-72.

9. Johnson RM. Ektacytometry of red blood cells. Subcell Biochem 1994;23:161-203.

10. Streekstra GJ, Hoekstra AG, Heethaar RM. Anomallous diffraction by arbitrarily oriented ellipsoids: applications in ektacytometry. Applied Optics 1994;33:7.288-96.

11. Shin S, Ku Y, Park MS, Jnag JH, Suth JS. Rapid cell-deformability system based on slit-flow laser diffractory with decreasing preassure differential. Biosens Bioelectron 2005;20:1.291-7.

12. Beutler E, Lichtman M, Coller BS, Kipps TJ. Williams Hematology 1995. 5.ed. New York, Mc Graw-Hill;1:406-41.

13. Lee GR, Forster J, Lukens J, Paraskevas F, Greer JP, Rodgers GM. Wintrobe's Clinical Hematology. Baltimore Lippincott Willians \& Wilkins 1999 10.ed.; 1:193-227.

14. Chien S. Determinants of blood viscosity and red cell deformability. Scand J Clin Lab Invest 1981;41:7-12.

15. Baskurt OK, Meiselman HJ. Cellular determinants of low-shear blood viscosity. Biorheology 1997;34:235-47.

16. Levander OA, Morris VC. Effect of iron deficiency on the filterability of rat red bllod cells. Fed Proc1 978;37:487. 
17. Tillmann W, Schöter W. Deformability of erytrocytes in iron deficiency anemia. Blut 1980; 40:179-86.

18. Yip R, Mohandas N, Clark M, Jain S, Shohet BS, Dallman PR. Red cell membrane stiffness in iron deficiency. Blood 1983;162:99-106.

19. Reinhart WH. The influence of iron deficiency on erythrocyte deformability. Br J Haematol 1992;80:550-5.

20. Anderson C, Aronson I, Jacobs P. Erythrocyte deformability is reduced and fragility increased by iron deficiency. Hematology 2000;4:457-60

21. Reinhart WH, Singh A. Erythrocyte aggregation: the roles of cell deformability and geometry. Eur J Clin Invest 1990;20:458-62.

22. Evans CR, Chapman D. Red blood cell biomembrane structure and deformability. Scand J Clin Lab Invest 1981;41:99-109.

23. Hochmut RM. Deformability and viscoelasticity of human erythrocyte membrane. Scand J Clin Lab Invest 1981;41:63-6.

24. Lux SE, Forget BG, Platt OS. Inherited disorders of the red blood cell membrane. American Society of Hematology (ASH) 1996:1-9.

25. Silveira P, Cynober T, Dhermy D, Mohandas N, Tchernia G. Red blood cell abnormalities in hereditary elliptocytosis and their relevance to variable clinical expression. Am J Clin Pathol 1997; 108:391-9.

26. Perez S, Milani A, Acosta L, Rasia RJ. New evidence of red blood cell rheological disorders in beta-thalassemia minor. Clin Hemorheol Microcirc 2004;31:89-96.

27. Saad GMP, Silveira, PAA. Avaliação da deformabilidade eritrocitária através da ectacitometria na deficiência de ferro. Rev Bras Hematol Hemoter 2003;25:267-268.

28. Vaya A, Simo M, Santaolaria M, Todoli J, Aznar J. Red blood cell deformability in iron deficiency. Clin Hemorheol Microcirc 2005; 33:75-80.

29. Akins PT, Gleen S, Nemeth PM, Derdeyn CP. Carotid artery thrombus associated with severe iron deficiency anemia and thrombocytosis. Stroke1996;27:1002-5.

30. Izzo P, Spagnuolo A, Manicone A, Nazzaro P, Lauta VM. Reduced deformability of erytrocytes as features of congenital dyserytropoietic anaemia type II (HEMPAS). Clin Hemorheol Microcirc 1999; 21:425-30.

31. Schauf B, Mannshreck B, Becker S, Dietz K, Wallwiener D, Aydeniz B. Evaluation of red blood cell deformability and uterine blood flow in pregnant women with preeclampsia and reduced uterine blood flow following the intravenous application of magnesium. Hypertens Pregnancy 2004;23:331-43.

32. Brown CD, Ghali HS, Zhao Z, Thomas LL, Friedman EA. Association of reduced red blood cell deformability and diabetic nephopathy. Kidney Int 2005;67:2066-7.

33. Biesida GK, Krzemien J, Czepiel, J, Teleglow, A, Dabrowski Z, Spodaryk K, et al. Rheological properties of erythrocytes in patients suffering from erysipelas. Examination with LORCA device. Clin Hemorheol Microcirc 2006;34:383-909.

Avaliação: Editor e dois revisores externos

Conflito de interesse: não declarado

Recebido: 23/01/2005

Aceito após modificações: 25/09/2006 